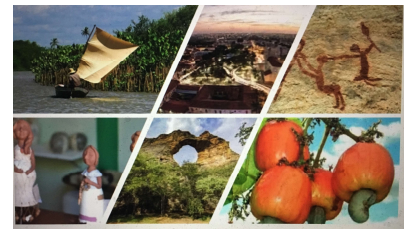

ISBN: 2675-1496 DOI: https://doi.org/10.26694/caedu.v1i2.9910

\title{
Olha que COISA MAIS LINDA? Quatro mulheres num mar de desafios
}

\author{
Gislene Danielle de Carvalho \\ Mestranda em Educação pela Universidade Federal do Piauí \\ Professora Substituta do Curso de Música da Universidade Federal do Piauí \\ ORCID: http://orcid.org/0000-0002-7860-7721
}

Ednardo Monteiro Gonzaga do Monti Doutor em Educação pela Universidade do Estado do Rio de Janeiro Professor do Programa de Pós-graduação em Educação da Universidade Federal do

Piauí

ORCID: https://orcid.org/0000-0003-3513-3316

\begin{abstract}
RESUMO
O presente artigo analisa a perspectiva educativa da primeira temporada da série "Coisa Mais Linda" apresentada pela Netflix. A série traz quatro protagonistas com experiências distintas, em uma grande capital do Brasil, no início da década de 60. O artigo está estruturado em três tópicos. No primeiro trata-se sobre os familiares conservadores e suas influências sobre as quatro personagens, segue com interpretações sobre os desafios das mulheres no ambiente de trabalho, no qual pode-se refletir sobre o feminismo e o lugar da mulher negra dentro do movimento, e por último, apresentamos os avanços que as trajetórias das protagonistas indicam sobre as conquistas das mulheres nas décadas intermediárias do século XX. Nessa análise são mobilizadas as ideias de Norbert Elias e John L. Scotson (1994) como pensamento principal fundamentado no conceito de estabelecidos e outsiders, a perspectiva de Luis Felipe Miguel e Flávia Biroli (2014), sobre o feminismo e política e a discussão sobre a questão da mulher negra no Brasil por meio da análise de José Carlos Reis (2010). Como resultado é possível compreender que as quatro protagonistas de "Coisa Mais Linda" não encerram em si mesmas todas as vivências do gênero feminino no Brasil, porém, são capazes de nos fazer refletir sobre o enfretamento da dominância masculina e em como a solidariedade em as mulheres é útil para a emancipação desse grupo.
\end{abstract}

Palavras-chave: História da Educação. Mulheres no Brasil. Netflix.

Look what most beautiful thing? Four women in a sea of challenges

Revista Caminhos da Educação: diálogos, culturas e diversidades. CAEDU/UFPI

Teresina, Brasil, v. 1, n. 2, p. 60-86, maio/agosto de 2019.

ISBN: 2675-1496 DOI: https://doi.org/10.26694/caedu.v1i2.9910 


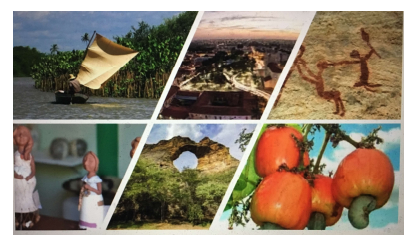

ISBN: 2675-1496 DOI: https://doi.org/10.26694/caedu.v1i2.9910

\begin{abstract}
This article analyzes the educational perspective of the first season of the "Most Beautiful Thing" series presented by Netflix. The series features four protagonists with different experiences in a large Brazilian capital in the early 60's. The article is structured in three topics. The first deals with conservative family members and their influence on the four characters, follows with interpretations of women's challenges in the workplace, in which one can reflect on feminism and the place of black women within the movement, and Finally, we present the advances that the trajectories of the protagonists indicate about the achievements of women in the middle decades of the twentieth century. In this analysis the ideas of Norbert Elias and John L. Scotson (1994) are mobilized as main thinking based on the concept of established and outsiders, the perspective of Luis Felipe Miguel and Flávia Biroli (2014), about feminism and politics and the discussion about the issue of black women in Brazil through the analysis of José Carlos Reis (2010). As a result it is possible to understand that the four protagonists of "Thing More Beautiful" do not contain in themselves all the experiences of the female gender in Brazil, but they are able to make us reflect on the confrontation of male dominance and on how solidarity in women. women is useful for the emancipation of this group.
\end{abstract}

Keywords: 1960s. History of Education. Women in Brazil. Netflix.

\title{
Mira qué COSA MAS LINDA? Cuatro mujeres en um mar de desafíos
}

\section{RESUMEN}

Este artículo analiza la perspectiva educativa de la primera temporada de la serie "La cosa más bella" presentada por Netflix. La serie presenta a cuatro protagonistas con diferentes experiencias en una gran capital brasileña a principios de los años 60. El artículo está estructurado en tres temas. El primer trato con miembros conservadores de la familia y su influencia en los cuatro personajes, sigue con interpretaciones de los desafíos de las mujeres en el lugar de trabajo, en el que uno puede reflexionar sobre el feminismo y el lugar de las mujeres negras dentro del movimiento, y Finalmente, presentamos los avances que las trayectorias de las protagonistas indican sobre los logros de las mujeres en las décadas intermedias del siglo XX. En este análisis, las ideas de Norbert Elias y John L. Scotson (1994) se movilizan como pensamiento principal basado en el concepto de personas establecidas y externas, la perspectiva de Luis Felipe Miguel y Flávia Biroli (2014), sobre el feminismo y la política y la discusión sobre El tema de las mujeres negras en Brasil a través del análisis de José Carlos Reis (2010). Como resultado, es posible comprender que los cuatro protagonistas de "Cosa más bella" no contienen en sí mismos todas las experiencias del género femenino en Brasil, pero pueden hacernos reflexionar sobre la confrontación del dominio masculino y sobre la solidaridad en las mujeres. La mujer es útil para la emancipación de este grupo.

Palabras clave: 1960 . Historia de la educación. Mujeres em Brasil. Netflix.

Teresina, Brasil, v. 1, n. 2, p. 60-86, maio/agosto de 2019.

ISBN: 2675-1496 DOI: https://doi.org/10.26694/caedu.v1i2.9910 


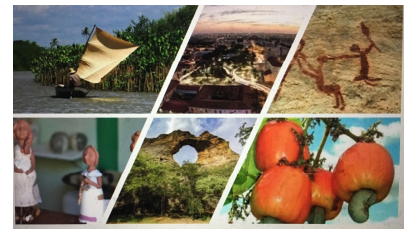

ISBN: 2675-1496 DOI: https://doi.org/10.26694/caedu.v1i2.9910

\section{INTRODUÇÃO}

Este texto alteia a perspectiva educativa da série "Coisa Mais Linda" veiculada pela Netflix. Estreada em 2019 e ambientada no início da década de 1960, quatro protagonistas com experiências de vida diferentes estão enlaçadas por um ponto em comum: lidar com a dificuldade de ser mulher num mundo de dominância masculina. Acreditando na possibilidade de uma série de streaming fomentar reflexões na perspectiva da história da educação três âmbitos foram levados em conta para nortear esse artigo. O ponto inicial é como a primeira temporada da série situa as quatro personagens principais socialmente? Que características sociais podem ter em comum quatro mulheres com vivências distintas, numa importante capital do Brasil? Como elas seriam vistas dentro dos seus ambientes sociais e núcleos familiares? Outra perspectiva se dá a respeito da situação das personagens no ambiente de trabalho. Quais os desafios que as quatro mulheres enfrentam diante das condições de trabalho, e até que ponto esses obstáculos são semelhantes, levando-se em conta a distinção da situação de cada personagem? E em terceiro, a reflexão se dá sobre os avanços. Que tipo de progresso as mulheres retratadas conseguem alcançar em suas jornadas nessa primeira temporada e como podemos compreender esse desenvolvimento das personagens sob uma ótica educativa?

O alcance do serviço de streaming Netflix no Brasil, em junho de 2019, de acordo com a Revista Exame Abril, online, foi de 27 milhões de usuários. Nosso país é o segundo que mais acessou à plataforma depois dos Estados Unidos, em 2011. Isso significa que o alcance de uma série que pode ser vista em casa, do computador ou mesmo do celular é bastante abrangente. Então, por que não benificiar-se para vê-la com olhos de educador? Não seria então uma boa oportunidade de uso nas aulas de História da Educação?

Figura 1: IMAGEM PROMOCIONAL COM A DATA DA ESTREIA DA SÉRIE 


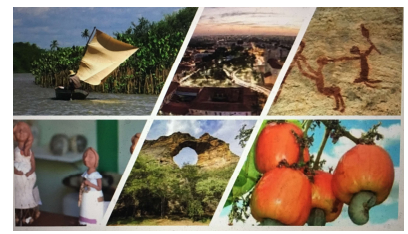

ISBN: 2675-1496 DOI: https://doi.org/10.26694/caedu.v1i2.9910

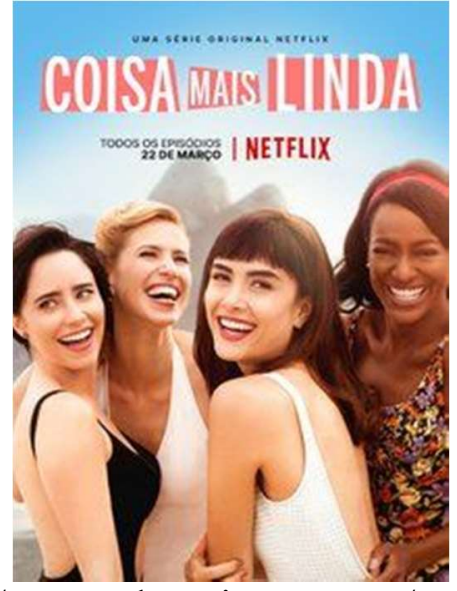

Figura 1 - http://www.adorocinema.com/series/serie-22943/

Em Coisa mais linda, há quatro figuras femininas que encabeçam o enredo: Maria Luiza Carone Furtado (Malu) interpretada por Maria Casadevall, Adélia Araújo pela atriz PathyDejesus, Thereza Soares representado por Mel Lisboa e Lígia Soares concebido por Fernanda Vasconcelos. A série foi criada por Giuliano Cedroni e Heather Roth e tem na direção Caíto Ortiz, Hugo Prata e Julia Rezende. A primeira temporada conta com sete episódios com a classificação etária de dezesseis anos.

A trama se passa principalmente na cidade do Rio de Janeiro e em alguns poucos momentos em São Paulo. Na cidade maravilhosa os ambientes explorados são a praia, o morro, um clube frequentado pela alta sociedade carioca, e sobreturo a casa de show "Coisa mais linda", que abriga em termos de música a bossa nova, gênero musical então recém elaborado à época apresentada pela série, assim também como o samba, que é citado como vindo do morro e o jazz. O público-alvo da casa seriam pessoas das mais diferentes contextos, propondo-se como um lugar sem preconceitos.

Cada protagonista tem em torno de si uma rede familiar e de contatos, e um enredo próprio que vislumbra o enfrentamento de situações de dominação masculina. O ponto em comum das quatro é o clube de música já citado, denominado Coisa mais linda. A escolha do nome foi feita pela personagem Malu, com a intenção de aludir a uma frase da música Garota de Ipanema de Tom Jobim e Vinícius de Morais. Uma licença poética 


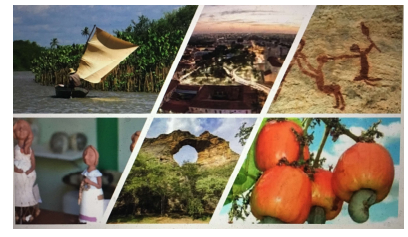

ISBN: 2675-1496 DOI: https://doi.org/10.26694/caedu.v1i2.9910

se dá nessa escolha, visto que o clube Coisa Mais Linda foi inaugurado em 1959 e a música Garota de Ipanema só seria composta em 1962.

Maria Luiza Carone Furtado (Malu) é dentre as protagonistas a que aparece primeiro na trama e sua paixão pela música, principalmente a então recém lançada bossa nova é o que a estimula ao crescimento diante das adversidades que encontra. No início da história Malu, que vem de uma família dona de fazendas de café, do estado de São Paulo, tem como núcleo familiar os pais Ademar Carone (João Bourbonnais), Ester Carone (Ondina Clovis Castilho) e o filho Carlos Carone Furtado (Enrico Cazzola). O marido de Malu, Pedro, embora só seja visto pela sua silhueta durante a primeira temporada, é um personagem importante por ser o que faz Maria Luiza sair da casa dos pais em São Paulo para viver no Rio de Janeiro.

Os dois tinham um acordo para montarem um restaurante no Rio, mas Pedro envolve-se com outras ações nos meses que antecedem a ida de Malu. Pedro se relaciona com outras mulheres, contrai muitas dívidas e termina por não cumprir sua parte. Malu sem saber o que acontecia no Rio vai à data marcada imaginando encontrar Pedro com o estabelecimento em vésperas de inauguração. Ao contrário, seguindo o endereço deixado pelo marido vai parar em um apartamento simples no Rio de Janeiro e depara-se com um restaurante inexistente. O pior de tudo para a personagem é ausência de Pedro que a princípio ela pensa ter sido até vítima de sequestro, sendo dissuadida dessa ideia a partir dos fatos com os quais se depara.

Francisco Carvalho (Chico) é um músico (cantor e compositor de bossa nova) que Malu conhece no seu primeiro dia na nova cidade. Os dois terminam por ter um relacionamento amoroso. O interessante sobre Chico é que ele não aparece como um homem que vem salvar Malu de suas dificuldades, pelo contrário, ele é emocionalmente inseguro e subaproveito seu talento, cabendo a ela o papel de levá-lo a uma nova perspectiva. Presentes na rede de sociabilidade de Maria Luiza também estão o dono da gravadora contratante de Chico, o Roberto (Gustavo Machado) e o fornecedor de bebidas que atende por Nanico (Paulo Tiefenthaler). 


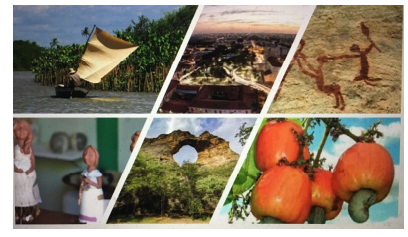

ISBN: 2675-1496 DOI: https://doi.org/10.26694/caedu.v1i2.9910

Adélia Araújo é uma personagem com características bem diferentes da personagem Malu. Negra, mãe solteira, mora numa comunidade sediada num morro carioca com a irmã Ivone Araújo (Larissa Nunes) e a filha Conceição Araújo (Sarah Vitória). O namorado de Adélia, um músico negro chamado Capitão (Ícaro Silva) acredita ser o pai de Conceição, mas ao longo da trama é revelado que o verdadeiro pai da menina é um homem branco da elite social da cidade, ex-patrão de Adélia. Ela é analfabeta e trabalha para uma patroa branca e insensível a vê-la como um ser humano. O seu primeiro contato com Malu é no prédio onde trabalha, no qual Malu vai morar chegando ao Rio. A cena de encontro das duas mostra as diferenças ideológicas entre elas no quesito enfrentamento das dificuldades da vida. Adélia salva Malu de um princípio de incêndio provocado por esta quando a mesma descobre ter sido enganada e abandonada pelo marido. Na ocasião Adélia já aparece como uma mulher otimista mesmo diante de obstáculos que para Maria Luiza pareciam intransponíveis.

Thereza Soares é a mais diferente das quatro personagens principais. É casada com Nelson Soares, morava em Paris antes de voltar para o Rio e trabalha na redação de uma revista escrita predominantemente por homens direcionada ao público feminino. Uma peculiaridade do casamento de Thereza é a opção por um matrimônio no qual a monogamia não é relevante. Além disso, o relacionamento com pessoas do mesmo sexo também não é tabu para o casal. Com essas aberturas e contexto familiar a luta contra a dominação masculina da personagem se dá no trabalho. A revista na qual Thereza trabalha segue à risca o conceito de "feminino" apresentado por Miguel (2014) a partir do livro de Simone de Beauvouir, O segundo sexo (1949): "um conjunto de determinações e expectativas destinado a cercear a capacidade de agência autônoma das mulheres".

Todas as matérias sugeridas pelo chefe de Thereza, o personagem Paulo Sérgio (Rodrigo Candelot), versam sobre situações que deveriam ser obrigatórias no cotidiano feminino, como preparações para encontros amorosos, tipos de roupas adequados e como se comportar em acordo com o que a sociedade espera da mulher. Beauvoir (1908-1986) é apontada por Miguel (2014) como uma fundadora central do feminismo contemporâneo 


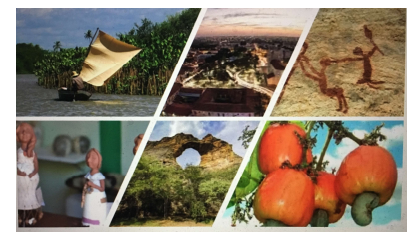

ISBN: 2675-1496 DOI: https://doi.org/10.26694/caedu.v1i2.9910

e mostra a frase do segundo volume de $O$ segundo sexo como um resumo da força de sua obra, o que nos leva também e a consumar o entendimento sobre a diferença entre feminino, descrito acima e feminismo: a mulher não é definida nem por seus hormônios nem por instintos misteriosos, mas pela maneira pela qual ela recupera, por meio de consciências alheias, seu corpo e sua relação com o mundo.(Beauvoir apud Miguel 2014 p. 27)

A luta feminista é exatamente essa, abrir espaço para um lugar da mulher na sociedade, no qual ela possa fazer escolhas sem se preocupar em agradar os homens e ainda ter condições de usufruir de igual para igual os benefícios da coletividade. Nem todas as feministas têm o discurso idêntico, tampouco apresentam as mesmas bandeiras, o que faz da luta ainda mais rica. Afinal cada ser humano tem suas idiossincrasias e com as mulheres isso não poderia ser diferente.

Numa outra perspectiva, Lígia Soares é a típica boa esposa casada com Augusto Soares (Gustavo Vaz) um aspirante a cargo político que não poupa esforços para impressionar o círculo político no qual transita. É concunhada de Thereza. A sogra de ambas, Eleonora Soares (Esther Góes), é uma mulher conservadora e machista, preocupada com as aparências e, sobretudo, com o prestígio do nome da família. Lígia sofre abusos no casamento e tem o sonho de tornar-se cantora, sonho esse abafado pela violência do marido. Mesmo diante dos abusos, Lígia começa relutante a desvencilhar-se do casamento, de todas as protagonistas ela é a que mais apresenta as características femininas esperadas pela dominação masculina: beleza, subserviência e falta de perspectiva de crescimento pessoal.

Nessa análise são mobilizadas as ideias de Norbert Elias e John L. Scotson (1994) como pensamento principal fundamentado no conceito de estabelecidos e outsiders apresentado na obra Os Estabelecidos e os Outsiders (1994). A luta feminista sob o olhar de Luis Felipe Miguel e Flávia Biroli (2014), contida no livro Feminismo e Política e a discussão sobre a questão da mulher negra no Brasil através da análise de José Carlos Reis (2010) no livro O Desafio Historiográfico (2010). 


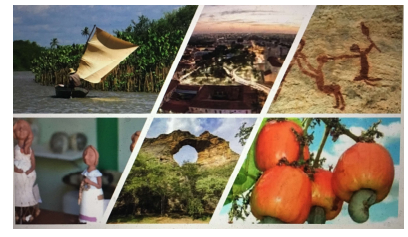

ISBN: 2675-1496 DOI: https://doi.org/10.26694/caedu.v1i2.9910

$\mathrm{O}$ artigo está estruturado em três tópicos. No primeiro trata-se sobre os familiares conservadores e suas influências sobre as quatro protagonistas da série. Segue com interpretações sobre os desafios das mulheres no ambiente de trabalho, no qual podemos cogitar sobre o feminismo e o lugar da mulher negra dentro desse movimento. E, por último, apresentamos os avanços que as trajetórias das personagens indicam sobre as conquistas das mulheres nas décadas intermediárias do século XX.

\section{MÃES, PAIS E MARIDOS CONSERVADORES}

Estabelecidos e Outsiders são conceitos que Elias e Scotson (2000) nos trazem, no livre que leva esse nome, como conclusão de uma pesquisa realizada em comunidade real chamada ficticiamente de Winston Parva, uma pequena cidade da Inglaterra. Como características do grupo dos estabelecidos temos: poder, coesão, tradição, autoridade, influência, autopercepção como um grupo "bom" e "merecedor" de todos os direitos. Aos outsiders cabe exatamente o contrário: uma autopercepção de estar em um nível abaixo, a falta de visão de si mesmo como um grupo que pode ser coeso e certa aceitação da situação como algo intransponível. No momento em que outsiders percebem-se e mudam o comportamento a reação dos estabelecidos é na maioria das vezes violenta, porém através da junção de elementos como coesão e determinação de mudança de paradigmas é possível que avanços sociais aconteçam.

A dominação masculina não é a única batalha a ser enfrentada pelas protagonistas de Coisa Mais Linda. Um olhar articulado com os conceitos de Norbert Elias e John L. Scotson permitem perceber que elas estão, cada uma na sua realidade, dentro do grupo dos outsiders e nem sempre isso se dá apenas em relação aos homens. Outras mulheres também podem estar no grupo antagonista (os estabelecidos) como é o caso da personagem Eleonora Soares (Esther Góes), que embora não apareça em muitas cenas durante a temporada, sua presença habitalmente vem acompanhada de conceitos machistas e preconceituosos com relação às noras, principalmente sobre Lígia. Vejamos dois exemplos. 


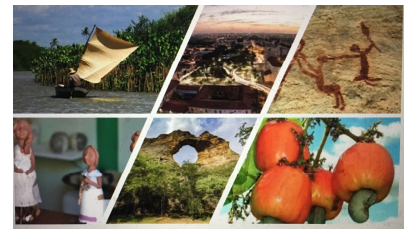

ISBN: 2675-1496 DOI: https://doi.org/10.26694/caedu.v1i2.9910

O primeiro diálogo transcrito a seguir, refere-se um momento em família, no qualestão presentes Nelson e a esposa Thereza, Augusto e a esposa Lígia. Logo na chegada Eleonora, senhora transeunte na elite carioca, faz comentários depreciativos à aparência de Augusto (filho) e de Lígia (nora). Ao dizer que o filho está "acabado" mostra uma preocupação com a aparência exterior, sugerindo que isso é de suma importância, possivelmente em detrimento até mesmo da situação emocional. Em outras situações ao longo da temporada, a personagem Eleonora tem como discurso recorrente o cuidado com as aparências perante a sociedade carioca. Nessa fração de conversa, nota-se também o reforço ao papel que "deve" ter a nora, o papel de procriadora e cuidadora do marido, para a qual recai a culpa pela aparência "acabada" do cônjuge. O seguinte diálogo se passa na sala do apartamento de Thereza e Nelson. Encontram-se conversando o casal anfitrião e o casal Lígia e Augusto, logo na chegada Eleonora dispara:

Eleonora: Olá!

Augusto: A senhora está linda como sempre.

Eleonora (respondendo ao filho): Que cara! Tá acabado.

(Voltando-se para a nora): Lígia, você não está cuidando direito do seu marido. (abraçando-a): Olha se não der uma encorpada vai ser difícil parir o meu primeiro neto! E você sabe que eu só estou esperando isso para morrer em paz.

(COISA MAIS LINDA, TEMPORADA 1, EPISÓDIO 4, 2019)

Já o segundo diálogo, se passa em outro momento, quando Lígia já está separada do marido - Augusto - por causa dos maus tratos e finalmente tenta vivenciar a experiência como cantora que em todo o tempo acalentou. A reprovação de Eleonora com relação à Lígia é implacável, uma forma de manter o seu lugar de matrona. Como uma senhora viúva Eleonora assume o papel de guardiã do bom nome da família. Na Frente da porta do clube Coisa mais linda.

Eleonora: Eu vim só entregar o documento do desquite. $\mathrm{O}$ Augusto está na Itália, ocupado com o prefeito, então eu estou cuidando desses assuntos para ele. Lígia quanto antes você sumir da nossa família melhor. 


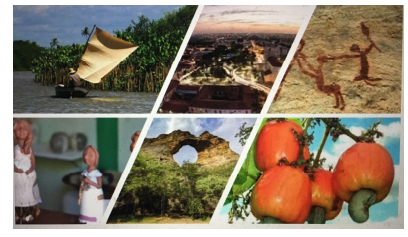

ISBN: 2675-1496 DOI: https://doi.org/10.26694/caedu.v1i2.9910

Lígia: $\quad$ Eu não fiz nada além de amar seu filho de forma incondicional, até quando ele, até quando era impossível para mim, Dona Eleonora, e é assim que a senhora me agradece?

Eleonora: Agradecer do quê? Da humilhação e da vergonha que você nos fez passar?

Lígia: $\quad$ É isso que o Augusto quer?

Eleonora: Mas eu achei que você ficaria feliz, que você ia ficar livre para viver essa vida de sonho que você escolheu.

Lígia: $\quad$ Olha, eu não espero que você entenda.

Eleonora: Mas entender o que? Que você acha mais importante do que a reputação da sua família?

Lígia: $\quad$ Da sua família, você quer dizer, não é?

Eleonora: Que surpresa Liginha. Eu esperava este comportamento da Thereza, não de você. Eu sempre achei que você fosse minha nora boazinha.

Lígia: $\quad$ Eu saí de casa porque o seu filho me batia.

Eleonora (depois de um breve silêncio): Você fala como se não tivesse dado motivo. Casamento é assim mesmo. Os homens têm lá seus dias piores, cabe a nós dar todo o apoio.

(COISA MAIS LINDA, TEMPORADA 1, EPISÓDIO 6, 2019)

Lígia sofre com as considerações da sogra e o comportamento do marido. Desenhando-se claramente que o seu papel na família é de coadjuvante, que é a esposa enfeite usada para adornar e de quem os estabelecidos (sogra e marido) esperam um comportamento irrepreensível para que ela continue sendo aceita como membro.

Outra mãe de família que segue o modelo da boa dona de casa para assim ser aceita pelos estabelecidos é Ester Carone, mãe de Maria Luiza. Ao longo da trama a personagem mostra novas facetas, mas no episódio inicial, um breve diálogo entre Malu e a mãe revela o quanto Ester se anula para manter o seu papel de boa esposa. $\mathrm{Na}$ Casa da família Carone, em São Paulo, num jantar de despedida que está sendo dado em homenagem à Maria Luiza.

Maria Luiza: $\quad$ Mãe, você trocou o vestido?

Ester: $\quad$ Ah! Seu pai não gostou do outro. Marido feliz, vida feliz. 


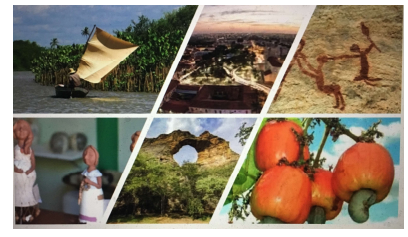

ISBN: 2675-1496 DOI: https://doi.org/10.26694/caedu.v1i2.9910

Maria Luiza: Hum. Esse é que é teu segredo para 30 anos de casada?

Ester: $\quad$ Um deles.

(COISA MAIS LINDA, TEMPORADA 1, EPÍSODIO 1 2019)

Tanto Eleonora, quando Ester comportam-se como Elias e Scotson (2000) descrevem quando dizem que se um indivíduo do grupo estabelecido se desvia do padrão do grupo, imediatamente ele perde poder e tem um rebaixamento de status. Assim como

participação na superioridade de um grupo e em seu carisma grupal singular é, por assim dizer, a recompensa pela submissão às normas específicas do grupo. Esse preço tem que ser individualmente pago por cada um de seus membros, através da sujeição de sua conduta a padrões específicos de controle dos afetos.

(ELIAS; SCOTSON, 2000, p. 26)

Então, para manter-se dentro do círculo a elas comum, as duas procuram ter atitudes e discursos que asseguram os seus lugares dentro desse grupo social da elite que frequentam.

Uma das armas mais eficazes para a manutenção do equilíbrio estabelecidooutsider é a estigmatização do grupo outsider pelo grupo estabelecido. Quanto a isso Elias e Scotson (2000) consideram: "Um grupo só pode estigmatizar outro com eficácia quando está bem instalado em posições de poder das quais o grupo estigmatizado é excluído." $\mathrm{Na}$ série essa estigmatização é vista em vários momentos.

Quando o pai da personagem Malu, o Sr. Ademar Carone, sabe que os planos da filha não correram como o planejado, tenta persuadi-la de não ficar sozinha no Rio de Janeiro. Maria Luiza, por sua vez, procura explicar a oportunidade que vislumbra para finalmente ter uma identidade própria. Diante da recusa da filha, Ademar imediatamente usa o seu poder financeiro para cercear a iniciativa da filha:

Malu: $\quad$ Eu quero transformar o restaurante em um clube de música, um lugar onde as pessoas queiram se 


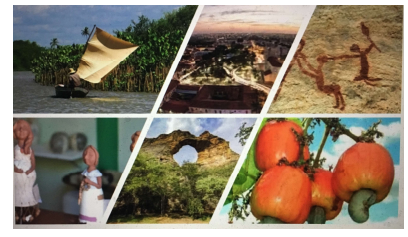

ISBN: 2675-1496 DOI: https://doi.org/10.26694/caedu.v1i2.9910

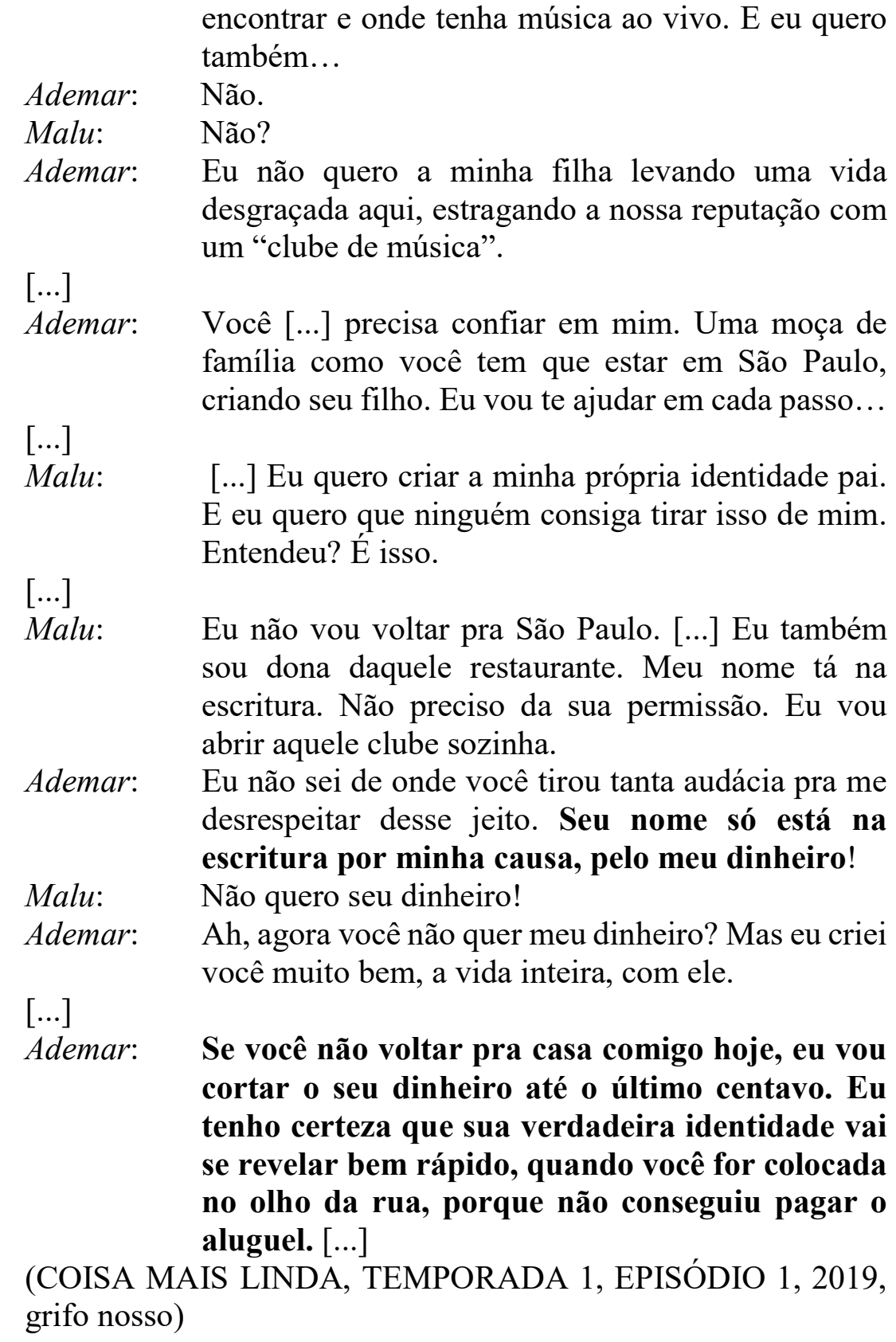

Nem sempre a questão financeira é o instrumento principal de separação entre estabelecidos e outsiders, outras questões como ser de uma família tradicional ou não pode ter tanto peso quanto isso. Ser um estabelecido é comungar de um padrão de pensamento de si como pertencente a um grupo, mas não é qualquer grupo, é um grupo

Teresina, Brasil, v. 1, n. 2, p. 60-86, maio/agosto de 2019.

ISBN: 2675-1496 DOI: https://doi.org/10.26694/caedu.v1i2.9910 


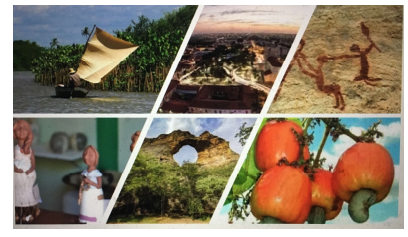

ISBN: 2675-1496 DOI: https://doi.org/10.26694/caedu.v1i2.9910

importante, um grupo que tem poder, um grupo que pode classificar as pessoas que estão fora dele como pessoas "piores", seres que não são dignos de frequentar os mesmos ambientes, e ainda que insistam não são dignos de participar das mesmas conversas.

As mães, pais e maridos conservadores em Coisa mais linda falam discurso semelhantes, a necessidade de manter a reputação da família. Qualquer comportamento fora desse padrão deve ser repreendido e aniquilado. Vemos isso nas relações e falas de Eleonora, a personagem que tem como marca essa preocupação constante. Chegando ao final da temporada os pais de Malu, conseguem cada um ao seu tempo, em alguma medida mudar a forma de ver a luta da filha. Eleonora segue até o final com a mesma postura personificando em si mesma as características citadas por Elias e Scotson como aquelas pertencentes ao grupo estabelecido: preocupações com a manutenção do poder, tradição, autoridade e merecimento de direitos.

Em outro episódio, na noite da inauguração do clube Coisa Mais linda, Chico (músico profissional que faz par romântico com a personagem de Maria Luiza) que deveria ser a principal atração da noite chega bêbado ao estabelecimento. Lígia que estaria acompanhando Augusto, em um jantar de cunho político com o prefeito, desentende-se com o marido e vai ao clube. Diante da falta de condições de Chico para conduzir o show, Malu pede que Lígia assuma o lugar de solista da noite.

Animada com o desempenho da amiga como cantora, na semana seguinte Maria Luiza pede que Thereza, coloque na revista em que trabalha, um anúncio sobre o clube e sobre a excelente participação de Lígia. Voltando à temática estigmatização, o referido anúncio traz uma consequência reprovativa da sociedade carioca para Malu e Lígia. Essa consequência é demonstrada em uma cena que se passa no clube elitizado que as três frequentam.

No referido clube, frequentado pela elite carioca, estão numa manhã, em uma mesa Thereza, Malu e Lígia. Enquanto conversam aproxima-se um funcionário a pedido de uma frequentadora que está em outra mesa e pede que Lígia e Malu se retirem. Imediatamente as três respondem negativamente, porém o funcionário é categórico 


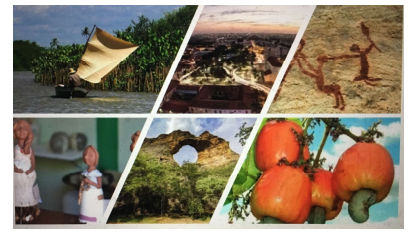

ISBN: 2675-1496 DOI: https://doi.org/10.26694/caedu.v1i2.9910

quanto à desqualificação das duas, alegando que elas não estão à altura dos padrões morais do estabelecimento.

Nessa cena tem-se um exemplo do que Elias e Scotson (2000) afirmam sobre as formas encontradas pelos estabelecidos para manter os outsiders em seu "lugar". Os autores asseveram que:

O grupo estabelecido sente-se compelido a repelir aquilo que vivencia como uma ameaça a sua superioridade de poder (em termos de sua coesão e seu monopólio dos cargos oficiais e das atividades de lazer) e a sua superioridade humana, a seu carisma coletivo, através de um contra-ataque, de uma rejeição e humilhações contínuas do outro grupo.

(ELIAS; SCOTSON, 2000, p. 33)

Lígia que inclusive era ainda sócia do clube agora é expulsa por ter quebrado várias regras importantes como sair de um casamento e tornar-se cantora, profissão que certamente não seria para uma moça de família. É interessante o crescimento da personagem ao longo da trama. Ela deixa de ser uma vítima de um casamento abusivo para ser uma mulher independente que assume as consequências de suas escolhas com maturidade, tendo o apoio das outras três protagonistas no enfrentamento das situações mais difíceis.

Quais os artifícios usados pelos conservadores para coibir a participação das mulheres que estão fora do grupo dos estabelecidos? Que outras situações podemos identificar como similares nos ambientes que frequentamos? Essas são duas das muitas questões que podem ser levantadas em sala de aula sobre o tema.

\section{DESAFIOS DAS MULHERES NO AMBIENTE DE TRABALHO}

Maria Luiza, Adélia e Thereza têm desafios diferentes no que diz respeito ao ambiente de trabalho. Lígia seria a única personagem que não encontra tais dificuldades dentro dessa esfera já que os obstáculos enfrentados por ela estão mais voltados a vencer os preconceitos para sair da vida de dona de casa para começar a trabalhar como cantora. 


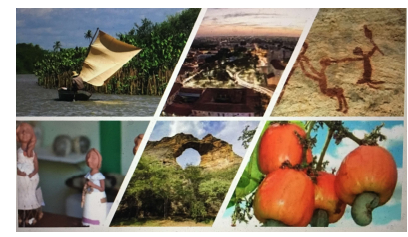

ISBN: 2675-1496 DOI: https://doi.org/10.26694/caedu.v1i2.9910

Na série seus problemas estão mais voltados pelo fato de contrariar a sogra e o marido, mas não exatamente pelo ambiente de trabalho em si.

Adélia e Maria Luiza se conhecem num momento muito delicado para uma delas. No primeiro contato entre elas, Adélia encontra Malu diante de labaredas causadas pela mesma no apartamento logo após sua descoberta da infidelidade e deslealdade do marido. A partir desse momento um laço de amizade começa a ser criado e por isso em cenas seguintes Maria Luiza, uma mulher traída pelo marido, convida Adélia, negra e pobre, para deixar seu emprego como doméstica e ir trabalhar com ela no futuro clube de música.

Para melhor contextualizar o ambiente de trabalho Adélia precisamos analisar algumas falas da sua patroa, uma personagem coadjuvante que carrega em si a opressão ao gênero e a falta de sensibilidade para ver Adélia, sua empregada doméstica como um ser humano que merece consideração como tal. O colóquio a seguir caracteriza bem essa situação. Na cena, Adélia leva Conceição ao trabalho porque a menina está doente. A patroa sai do elevador e encontra Adélia, Conceição e Maria Luiza:

Patroa: Olha só quem resolveu aparecer. E batendo papo no saguão, como uma rainha. Depois reclamam quando a gente chama eles de preguiçosos. E ainda trouxe a menina de novo.

Adélia: $\quad$ Desculpa o atraso Dona Regina, e a Conceição não vai mexer em nada.

Patroa: $\quad$ Adélia, você já trabalha pra mim há dois anos e você sabe como sou generosa.

Adélia: $\quad$ Sim senhora.

Patroa: $\quad$ Eu não faço você dormir aqui, eu deixo você levar minha roupa pra casa pra lavar. E ainda te dou folga no domingo.

Adélia: $\quad$ É eu sou muito agradecida.

Patroa: $\quad$ Eu vou te dar mais uma chance. Hoje você pode ir embora, porque eu vou passar o dia todo fora e não quero essa menina mexendo nas minhas coisas. Eu vou descontar o dia e fica tudo certo.

Adélia: $\quad$ Sem problema.

(COISA MAIS LINDA, TEMPORADA 1, EPISÓDIO 2, 2019)

Revista Caminhos da Educação: diálogos, culturas e diversidades. CAEDU/UFPI

Teresina, Brasil, v. 1, n. 2, p. 60-86, maio/agosto de 2019.

ISBN: 2675-1496 DOI: https://doi.org/10.26694/caedu.v1i2.9910 


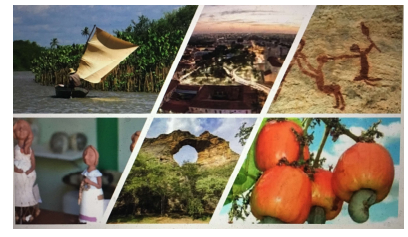

ISBN: 2675-1496 DOI: https://doi.org/10.26694/caedu.v1i2.9910

Nessa cena Adélia encarna algumas questões que as mulheres negras enfrentavam e ainda hoje enfrentam. Mãe solteira, precisa levar a filha ao trabalho, porque a mesma está doente e ela não tem condições de encaminhá-la para o atendimento médico. Hoje é bem mais fácil, em comparação com a época retratada na série, o acesso ao tratamento de saúde, porém, não quer dizer que esse atendimento seja eficaz ou de pronto para as pessoas de baixa renda. Uma das situações interessantes pra levar a sala de aula. A série está ambientada em 1959, mas e hoje em 2019? As empregadas domésticas já conseguiram realmente condições muito diferentes de tratamento e de trabalho, como podemos justificar essa resposta? O que está previsto na Lei Complementar $n^{\circ} 150$, de 2015 que regulamenta a Emenda Constitucional no 72 (PEC das Domésticas), realmente se dá em todas as residências, existe alguma forma de fazer essa análise? E quantitativamente existem mais ou menos mulheres negras, em comparação às mulheres brancas, exercendo a profissão de empregada doméstica, que pesquisas existem a respeito desse tema?

A condição do negro no Brasil, ainda hoje é maculada pela situação humilhante da escravidão e sua posterior abolição que terminou por chancelar um futuro incerto e doloroso por gerações. José Carlos Reis (2010) em seu livro O desafio historiográfico, traz no capítulo sexto uma análise do posicionamento de Gilberto Freyre em seu Casa Grande \& Senzala (1933). Segundo Reis (2010) o Brasil apresentado por Freyre (1933) é o de um país sem problemas raciais, onde todos nós, homens e mulheres, negros e brancos, temos um lugar tranquilo e seguro em sociedade, vivendo aqui pacificamente. $\mathrm{O}$ próprio discurso da patroa de Adélia traz um pouco dessa ilusão. Ela “deixa Adélia levar" as suas roupas pra lavar em casa, a patroa "não faz" Adélia dormir em sua casa e ainda, como se fosse enorme generosidade as folgas aos domingos. É quase um trabalho escravo, visto que o que Adélia recebe não permite nem que ela possa ter condições de levar a filha para o médico.

É importante essa conjuntura na medida em que ainda faz-se necessário um olhar para a desigualdade racial. Qual a porcentagem de negros em profissões bem remuneradas 


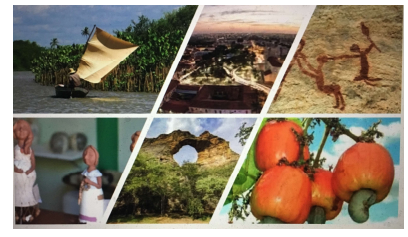

ISBN: 2675-1496 DOI: https://doi.org/10.26694/caedu.v1i2.9910

no Brasil? E de negras? Sim porque além das dificuldades enfrentadas pelos homens negros ainda existem outras que só as mulheres negras vivenciam. E são mais duras porque elas estão duas vezes discriminadas.

A série traz uma cena com diálogo primoroso a esse respeito. Malu convida Adélia para trabalhar no clube Coisa Mais linda. Adélia entra com a força de trabalho, já que não tem recursos financeiros. Em um dado momento uma forte chuva acaba com todo o esforço que elas já tinham feito. A reação de Maria Luiza mostra que sua relação de trabalho com Adélia não era naquele momento tão de igual para igual como parecia a princípio. Adélia traz em seu texto uma lição de vida que retrata a diferença entre as dificuldades da mulher negra e da mulher branca.

$\begin{array}{ll}\text { Malu: } & \text { Eu acabei de perder tudo. Tudo o que tinha. } \\ \text { Adélia: } & \text { Isso tá longe de ser o fim do mundo Malu. } \\ \text { Malu: } & \text { Pra mim é! É o fim do mundo. Não tenho mais nada. } \\ \text { Adélia: } & \text { Eu to aqui. Juntas a gente resolve isso, a gente já fez } \\ & \text { isso uma vez. } \\ \text { Malu: } & \text { Pelo amor de Deus Adélia. Não precisa fingir que } \\ & \text { você se importa. } \\ \text { Adélia: } & \text { Eu me importo.[...] } \\ \text { Malu: } & \text { Por quê? Se fui eu que abri mão da minha vida } \\ & \text { inteira pra conseguir fazer essa merda desse lugar. } \\ \text { Adélia: } & \text { Ah é! Você é a maior vítima do mundo inteiro.[...] } \\ \text { Malu: } & \text { Adélia! Adélia eu tava tão perto, cê entende? Eu } \\ & \text { tava lutando pelo meu direito de trabalhar, eu deixei } \\ & \text { meu filho na casa da minha mãe. Tô tentando fazer } \\ & \text { alguma coisa pela minha vida. Só que tá muito } \\ & \text { difícil! } \\ \text { Chega Malu! Para de olhar pro seu próprio umbigo } \\ \text { sdélia: } & \text { sua egoísta! Tudo eu! Eu fiz, eu perdi! Eu, eu, eu, } \\ & \text { eu. A gente perdeu! "Lutando pelo meu direito de } \\ & \text { trabalhar?" Eu trabalho desde os oito anos de idade. } \\ & \text { A minha avó nasceu numa senzala e é difícil. É bem } \\ & \text { difícil mesmo. Eu trabalhei seis, sete dias na } \\ & \text { semana. Saía de casa às quatro horas da manhã, } \\ & \text { ficava mais de uma hora ônibus na ida, mais uma } \\ & \text { hora no ônibus na volta e chegava em casa a } \\ & \text { Conceição tava dormindo. Tudo isso pra por um }\end{array}$




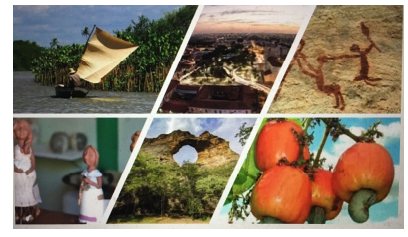

ISBN: 2675-1496 DOI: https://doi.org/10.26694/caedu.v1i2.9910

prato de comida na mesa. Isso sim pra mim é relevante.

(COISA MAIS LINDA, TEMPORADA 1, EPISÓDIO 3, 2019)

Enquanto para a mulher pobre restava a necessidade premente de trabalhar para o próprio sustento, a mulher da classe média era educada e orientada para ser a boa esposa e mesmo com essa diferença de perspectiva ambas estavam sujeitas à dominação masculina. Entretanto, essas mulheres da série fazem um esforço para romper com essa situação. Depois da cena citada anteriormente, Maria Luiza volta para casa em São Paulo e encontra na mãe um apoio que ela nunca poderia esperar. Recobrando o ânimo retorna ao Rio de Janeiro, procura Adélia e a convence de trabalhar em forma de sociedade a partir dali de igual para igual.

Já Thereza não enfrenta à princípio problemas com a dominação masculina na esfera domiciliar. Seus desafios encontram-se na redação da revista que trabalha. Embora a revista seja feminina, Thereza é a única redatora mulher, os outros são homens. As revistas dos anos 50 "traziam modelo de família - branca, de classe média, nuclear, hierárquica, com papéis definidos - regras de comportamento e opiniões sobre sexualidade, casamento, juventude, trabalho feminino e fidelidade conjugal" (BASSANEZI, 2004). Tudo isso escrito por quem? Por homens, que tinham certeza de saber o que as mulheres queriam e precisavam ler. Em um diálogo excelente para iniciar a discussão em sala de aula, Thereza tenta levar para a revista a vivência das mulheres que estavam trabalhando na construção de Brasília, a reação dos colegas de trabalho é a pior possível. Thereza, apontando para algumas fotos em cima da mesa diz:

Thereza: Como falta ainda um artigo pra completar a edição, a minha sugestão é falar sobre as mulheres que tão trabalhado na construção de Brasília. Elas são um terço, um terço da força de trabalho e ninguém fala absolutamente nada sobre elas na imprensa. Eu entrevistei essa mulher aqui [mostrando uma foto]. Ela saiu do Rio Grande do Norte, dirigindo um caminhão, grávida de sete meses pra chegar lá. E ela.[Dois colegas começam a rir e cochichar]. 


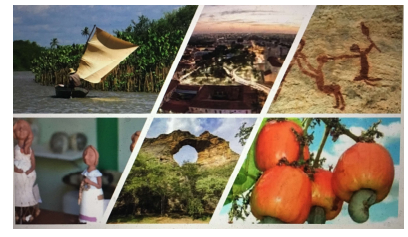

ISBN: 2675-1496 DOI: https://doi.org/10.26694/caedu.v1i2.9910

\begin{tabular}{|c|c|}
\hline hereza: & um problema Gustavo? \\
\hline Gustavo: & Pode continuar, pode continuar. \\
\hline hereza: & $\begin{array}{l}\text { Não, não. Se tiver alguma coisa te incomodando } \\
\text { pode falar. }\end{array}$ \\
\hline ustavo: & $\begin{array}{l}\text { Tudo bem. Mulher nenhuma se interessa por isso, } \\
\text { Thereza. }\end{array}$ \\
\hline hereza: & Ah não? \\
\hline ustavo: & $\begin{array}{l}\text { Só sapatão vai ler isso.[Risadas altas em coro por } \\
\text { parte dos outros homens na reunião.] }\end{array}$ \\
\hline Thereza: & E o que você sugere então? \\
\hline ustavo: & $\begin{array}{l}\text { Eu sei lá. Alguma coisa de tecido, de nova estação, } \\
\text { de tendência, eu não sei. Ou quem sabe como ser } \\
\text { generosa no seu decote, alguma coisa } \\
\text { assim.[Risadas generalizadas]. }\end{array}$ \\
\hline & $\begin{array}{l}f e \text { : Tá bom, tá bom meninas. Chega de gastar latim } \\
\text { com isso. Thereza, a sua ideia é boa. Eu acho que tá } \\
\text { na hora de falar de Brasília mesmo. É o assunto do } \\
\text { momento. Então que tal você voltar a focar no perfil } \\
\text { daquela Miss Brasília, como é que é o nome dela é } \\
\text { Marta não sei de que? }\end{array}$ \\
\hline & [fazendo uma mímica para mostrar o corpo \\
\hline
\end{tabular}

(COISA MAIS LINDA, TEMPORADA 1, EPISÓDIO 3, 2019)

Não é que homens não possam redigir uma revista voltada ao público feminino, ou vice-versa. Defender esse tipo de ideia pode ser retrógrado. A questão é que para falar de um gênero diferente do seu, se faz necessário uma empatia, uma sensibilidade e uma clareza de visão da situação social do outro. O diálogo acima mostra o contrário, homens preconceituosos e limitados para compreender o que o público feminino esperaria de uma revista, mesmo estando de frente para uma mulher argumentando sobre o que ela acreditava ser pertinente. Ainda assim, como mote para uma discussão em sala de aula, esse diálogo dá muitas oportunidades de reflexão.

Sobre a década de 50, Bassanezi (2004), destaca o que se esperava das mulheres e como estas poderiam ser classificadas de acordo com o comportamento:

As revistas da época classificavam as jovens em moças de família e moças levianas. Às primeiras, a moral dominante garantia o respeito social, a possibilidade de um casamento modelo e de uma 


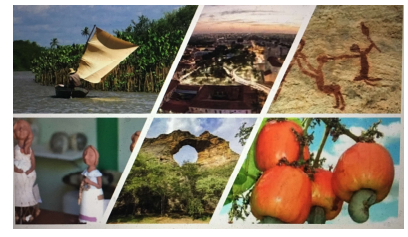

ISBN: 2675-1496 DOI: https://doi.org/10.26694/caedu.v1i2.9910

vida de rainha do lar - tudo o que seria negado às levianas. Estas se permitiam ter intimidades físicas com homens; na classificação da moral social estariam entre as moças de família, ou boas moças, e as prostitutas.As moças de família eram as que se portavam corretamente, de modo a não ficarem mal faladas. Tinham gestos contidos, respeitavam os pais, preparavam-se adequadamente para o casamento, conservavam sua inocência sexual e não se deixavam levar por intimidades físicas com os rapazes. Eram aconselhadas a comportarem-se de acordo com os princípios morais aceitos pela sociedade, mantendo-se virgens até o matrimônio enquanto aos rapazes era permitido ter experiências sexuais.

(BASSANEZI, 2004, p. 510)

Dois desafios encontrados pela personagem Malu em relação ao trabalho, foram diante de dois homens bem "distintos". Um era Roberto (Gustavo Machado), dono da gravadora com a qual Chico tinha contrato, e o outro era Nanico (Paulo Tienfenthaler) que se torna fornecedor exclusivo de bebidas para o clube Coisa Mais Linda.

Logo no primeiro episódio, Thereza - que trabalha como redatora em uma revista feminina -, ao ser apresentada à Malu - mentora do Coisa Mais Linda) - através de Lígia -cantora reprimida pela marido e a sogra -, convida Malu para ir a uma festa em um barco. O barco em questão pertencia à Roberto, o dono de uma gravadora, que logo flerta com Maria Luiza. Nesse mesmo barco Maria Luiza vê Chico tocando e cantando pela primeira vez. Roberto é a primeira pessoa que Malu procura para unir forças na montagem do seu clube, entretanto, é recebida com sarcasmo e incredulidade por parte de Roberto que nega sem mais delongas o auxílio que ela procura.

Nanico entra na rede de contatos de Malu de uma forma mais grosseira. Ela vai até ele em busca de informações sobre Pedro, seu ex-marido, e ele que é dono de um local usado para rinhas de galos, a recebe dizendo que Pedro tem grandes dívidas e que ela deveria saldá-las, não necessariamente com dinheiro, deixando nas entrelinhas a objetificação sexual dela. Apesar de Malu diante da situação ameaçadora não se apresentar como esposa de Pedro, Nanico descobre seu verdadeiro nome e toma ciência da abertura do clube Coisa Mais Linda. Então ele impõe sua presença obrigando-a a Revista Caminhos da Educação: diálogos, culturas e diversidades. CAEDU/UFPI

Teresina, Brasil, v. 1, n. 2, p. 60-86, maio/agosto de 2019.

ISBN: 2675-1496 DOI: https://doi.org/10.26694/caedu.v1i2.9910 


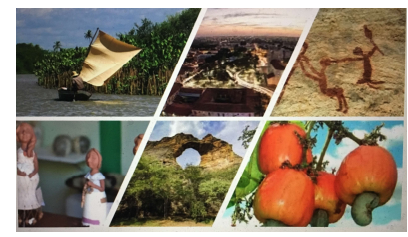

ISBN: 2675-1496 DOI: https://doi.org/10.26694/caedu.v1i2.9910

receber suas bebidas contrabandeadas no estabelecimento e ainda mais como único fornecedor.

Adélia, Malu e Thereza têm formas distintas de enfrentar as dificuldades, mas conseguem ao longo da trama sobressair-se, cada uma com sua personalidade, das situações que apresentam obstáculos para seu crescimento. Aprofundaremos mais sobre esse desfecho no tópico seguinte no qual trataremos dos avanços que as personagens conquistaram ao longo da história dessa primeira temporada da série.

\section{POSSÍVEIS AVANÇOS}

Um caminho interessante seguido pela série é o processo educativo de alguns personagens masculinos por meio do posicionamento das figuras femininas, no final da primeira temporada. Chico, par romântico de Malu, Nelson, marido de Thereza e Ademar, marido de Lígia, são levados a perceber de outra forma as protagonistas e fazem mudanças significativas em suas próprias vidas.

Chico começa a série como um talentoso cantor e compositor de bossa nova e tem um contrato na gravadora de Roberto. Mesmo assim mostra-se arredio em fazer shows e não consegue cumprir os prazos para a entrega de composições. Conhece Malu na festa no barco de Roberto no primeiro dia que ela chega ao Rio. Malu no momento em que conhece Chico ainda está atordoada com a nova situação da sua nova vida sem o marido, porém isso não impede que uma faísca seja acesa entre eles.

Uma contribuição de Chico para a experiência de Maria Luiza é o fato de ele levála para conhecer o samba no morro, esse convite faz com que ela amplie seus horizontes musicais e coloque o estilo como uma das atrações do seu clube. Depois de algumas idas e vindas amorosas entre os dois, Chico é convidado para fazer a inauguração do clube Coisa Mais Linda e chega bêbado, tem uma discussão com uma pessoa na plateia e não consegue terminar o show.

Depois desse episódio ele finalmente consegue com a ajuda de Maria Luiza fazer uma reflexão sobre o seu comportamento e no último episódio logra fazer um show de 


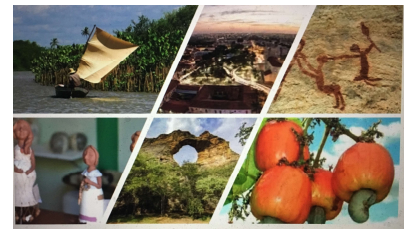

ISBN: 2675-1496 DOI: https://doi.org/10.26694/caedu.v1i2.9910

virada de ano tocando com um músico estrangeiro que o convida para o uma turnê. Maria Luiza apoia a decisão e o deixa confiante para essa nova etapa.

Outro personagem que também muda em relação à Maria Luiza é o seu pai, Ademar. No início da tramam, o empresário paulistano, tenta fazer com que a filha desista de ficar no Rio e ameaça tirar todo o apoio financeiro caso ela não obedeça a sua determinação. No episódio em que uma forte chuva destrói os preparativos para a inauguração do clube, depois da discussão com Adélia, Malu se dá por vencida e retorna à São Paulo.

Com a volta da filha, Ademar insiste que ela se case novamente porque essa seria a única chance dela continuar tendo uma vida digna. É comum o casamento imposto pelos padrões sociais como algo de extrema importância para a mulher, principalmente aquelas "das camadas mais elevadas da sociedade, para as quais se fomentavam as aspirações ao casamento e filhos, cabendo-lhes desempenhar um papel tradicional e restrito". (SOIHET, 2004). Manter o casamento era uma obrigação da feminina, então cabia a ela, suportar e se submeter a todas as situações advindas desse consórcio permanentemente para o bem do marido. Ester, a mãe de Malu, vendo que a filha está desanimada a chama para uma conversa e falando sobre sua própria experiência anterior:

\begin{tabular}{ll} 
Ester: & Tá tudo bem? Tá sentindo falta do Rio? \\
Malu: & Tô sentindo falta de sentir que eu tô no lugar certo. \\
& Como você. Mãe, lá no Rio, eu consegui ouvir a \\
& minha voz pela primeira vez. Sem o papai, sem o \\
& Pedro. \\
Ester: & Eu te entendo muito bem. \\
Malu: & Mesmo? \\
Ester: & Eu já fui jovem, mas você é muito mais esperta do \\
que eu. & \multicolumn{1}{c}{ Você acha? } \\
Malu: & Você sabe que você não pode mais voltar. \\
Ester: & Eu sei. Não vou mais deixar o Carlinhos. \\
Malu: & Não, não. Você não pode mais voltar pra cá, pra sua \\
Ester: & vida antiga, pra sua casa. Seria um erro. \\
Malu: & Você acha?
\end{tabular}




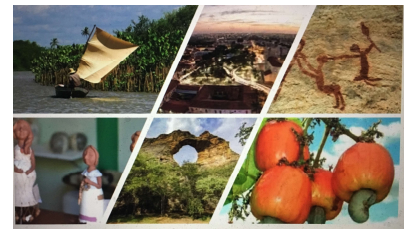

ISBN: 2675-1496 DOI: https://doi.org/10.26694/caedu.v1i2.9910

Ester: $\quad$ Não vai ter um dia da sua vida que você não vai se arrepender. Eu sei do que eu tô falando. (olhando para um bracelete que está usando) Esse bracelete.

Malu: $\quad$ Você não tira ele desde que eu era criança, eu me lembro.

Ester: $\quad$ O seu pai odeia.

Malu: $\quad$ Por quê?

Ester: $\quad$ Ele é uma lembrança da minha época de incertezas.

Eu também já deixei essa vida pra trás, mas eu voltei.

Malu: $\quad$ Por quê?

Ester: $\quad$ Por você. O seu pai nunca ia deixar eu te levar comigo. Eu tive que escolher. Mas eu não tinha com quem contar. Você tem. Você pode contar comigo. Você e o Carlinhos.

(COISA MAIS LINDA, TEMPORADA 1, EPISÓDIO 4, 2019)

Depois da conversa, no dia seguinte Malu volta para o Rio, faz as pazes e com Adélia. Com ânimo renovado convence Adélia a sair do emprego de doméstica e oferece metade dos lucros da futura casa de show. Malu consegue um empréstimo com Nanico e elas conseguem inaugurar o estabelecimento. Ademar então é surpreendido pelo primeiro pagamento de Malu por seu investimento no restaurante com Pedro, seu ex-marido, e entendendo o amadurecimento da filha, compreende que estava enganado e pede perdão a ela dentro do clube Coisa Mais Linda, reconhecendo seu erro.

Nelson, marido de Thereza, aparece no início como um homem mais liberal, por concordar com o fato de sua mulher trabalhar fora, além do acordo mútuo dentro do casamento para envolvimento sexual de ambos com outras pessoas, porém no final é revelado que Nelson é o pai da filha de Adélia. Ele e Adélia tiveram um romance quando ela era empregada doméstica em sua casa. Na época, a mãe de Nelson, Eleonora, o coage a viajar para Paris com intuito de que terminassem o romance. Nelson parte sem saber que Adélia estava grávida e deixa pra ela uma carta que nunca chega à sua destinatária. O reencontro dos dois se dá no clube Coisa Mais Linda, o romance reacende, mas Adélia agora mais madura, depois que dá a notícia da existência de Conceição nota que Nelson não tem a reação que ela gostaria. Thereza e Nelson perderam um filho quando moravam Revista Caminhos da Educação: diálogos, culturas e diversidades. CAEDU/UFPI

Teresina, Brasil, v. 1, n. 2, p. 60-86, maio/agosto de 2019.

ISBN: 2675-1496 DOI: https://doi.org/10.26694/caedu.v1i2.9910 


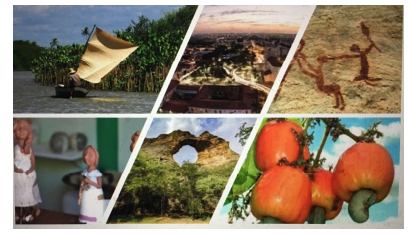

ISBN: 2675-1496 DOI: https://doi.org/10.26694/caedu.v1i2.9910

em Paris e depois disso ela não conseguiu mais ficar grávida. A existência da filha de Nelson com Adélia, de acordo com o julgamento dele seria um golpe muito duro para Thereza.

A partir dessa conjuntura Adélia afirma ter perdido o encanto por Nelson. Ele depois de fazer uma reflexão conta sobre Conceição, filha dele com a ex-doméstica negra, conta para Thereza a sua paternidade e ela o expulsa de casa. Nelson conta para a mãe, Eleonora, que tem uma filha e ela reage com preconceito e descrença sobre as intenções de Adélia. Eleonora orienta ao filho para deixar esse assunto esquecido e nunca se encontrar com sua filha, Conceição. Thereza e Nelson reatam o casamento e planejam uma volta a Paris para um novo começo. Com essa perspectiva Nelson então pede a Adélia para ver Conceição ao menos uma vez de longe antes de viajar.

As quatro protagonistas conseguem mudar o ambiente e as pessoas à sua volta, mas a mulher que muda o pensamento de Nelson é Conceição. A visão da menina faz com que ele desperte para o seu papel de pai e desista de ir embora para Paris. Thereza resolve ir sozinha. Sobre as mudanças na vida das personagens o caso de Thereza continua na contramão das outras três. Ela que começa com um casamento aberto e um trabalho fora de casa, termina conseguindo o cargo de redatora-chefe da revista e muda o comportamento nesse cargo agindo de uma forma bem parecida com Paulo Sérgio, seu ex-chefe. Uma inovação da sua gestão é o número de mulheres na redação da revista, mas o relacionamento que Thereza estabelece com elas é machista. Por fim, ela desiste do emprego para ir morar em Paris sem Nelson, porém isso não quer dizer que guarde algum rancor de Adélia, pelo contrário as duas continuam tendo uma boa convivência.

Augusto é um personagem que embora mude para pior, reconhece ao final da temporada que sua vida sem Lígia não tem sentido. Ele que encarna o homem machista, covarde, que bate na esposa mostra-se controlado pela mãe conservadora. Aspirando a um cargo político não hesitava em usar a esposa como moeda de troca no círculo masculino, aquiescendo em mostrá-la à todo momento bela nos eventos sociais para o deleite dos outros homens. Inclusive, por um lado, o político, fingia não escutar 


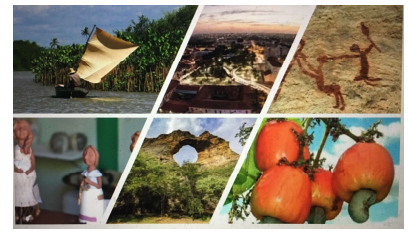

ISBN: 2675-1496 DOI: https://doi.org/10.26694/caedu.v1i2.9910

comentários grosseiros sobre a aparência de Lígia nos ambientes que frequenta. Por outro lado, o de marido chauvinista, desconta nela sua frustração usando até mesmo de violência sexual.

Quando Lígia finalmente consegue sair desse casamento, obriga a família do exmarido a sofrer as consequências da sua escolha perante o círculo político. Numa rede de sociabilidades na qual as relações harmoniosas de aparência valem mais do que a essência. Assim, Augusto perde a indicação que teria e passa a ser banido como opção política para a candidatura a um cargo político com o apoio do partido ao qual é vinculado.

Outro ponto em que Lígia pode ser citada é o fato de que a mesma ao descobrir que estava grávida no final do casamento, escolha fazer um aborto. Embora isso não seja tão explorado na série, (isso é percebido apenas por meio de fotos encomendadas por Eleonora a um detetive particular) causa um imenso impacto no desfecho do capítulo final da temporada. Sem sombra de dúvidas é assunto para discussão fora da série.

\section{CONSIDERAÇÕES FINAIS}

A partir dessas ponderações é possível conceber as possibilidades educativas de uma série de streaming são muitas. As quatro protagonistas de "Coisa Mais Linda" não encerram em si mesmas todas as vivências do gênero feminino no Brasil, porém, são capazes de nos fazer refletir sobre o enfretamento da dominância masculina e em como a solidariedade entre as mulheres é útil para a emancipação desse grupo. As condições de trabalho em 2019 são diferentes do início da década de 60, mas, através dos desafios apresentados para Malu, Adélia, Thereza e Lígia percebemos que a análise da ficção nos leva facilmente à discussão das mudanças e semelhanças nos dias atuais a respeito disso. A mulher negra ainda enfrenta dificuldades peculiares, a que trabalha fora de casa precisa conciliar dupla ou às vezes tripla jornada de trabalho, a casada muitas vezes sofre abusos no matrimônio. Mesmo assim, os avanços são notórios e significativos e audiência a essa obra é uma prova disso. 


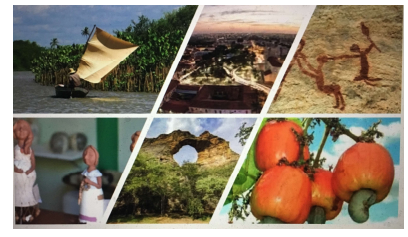

ISBN: 2675-1496 DOI: https://doi.org/10.26694/caedu.v1i2.9910

Silva e Monti (2019) no livroViagens pelo cinema: Convites à História da Educação, que "cinema é uma ferramenta acessível, e que pode contribuir para a democratização do acesso ao conhecimento científico [...] para além dos muros da universidade." Acreditando na mesma premissa concluímos que Coisa mais Linda é um prato cheio para reflexões ao trazer quatro protagonistas que se superam enquanto mulheres, que redefinem seu papel na sociedade e mudam as pessoas à sua volta. É uma série que abre várias possibilidades para a discussão dentro e fora da sala de aula.

\section{REFERENNCIAS}

BASSANEZI, Carla. Mulheres dos anos dourados. In: PRIORE, Mary del (Org.). História das Mulheres no Brasil. 7. ed. São Paulo: Contexto, 2004. p. 508-535. Organização de Textos: Carla Bassanezi.

ELIAS, Norbert; SCOTSON, John L..Os estabelecidos e os outsiders: sociologia das relações de poder a partir de uma pequena comunidade. Rio de Janeiro: Jorge Zahar, 2000. 224 p. Tradução de Vera Ribeiro.

MIGUEL, Luis Felipe; BIROLI, Flávia. Feminismo e Política. São Paulo: Bontempo, 2014. 164 p.

MONTI, Ednardo Monteiro Gonzaga. Canto Orfeônico: a linguagem musical em vozes políticas e educativas. Revista Teias (UERJ. Online), v. 12, p. 179-195, 2011.

MONTI, Ednardo Monteiro Gonzaga. Canto Orfeônico: Villa-Lobos e as Representações Sociais do Trabalho na Era Vargas. Revista Teias (UERJ. Online), v. 9, p. 78-90, 2008.

REIS, José Carlos. O desafio historiográfico. Rio de Janeiro: FGV, 2010.

SILVA, Alexandra Lima da; MONTI, Ednardo Monteiro Gonzaga do. Viagens pelo cinema: Convites à História da Educação. Teresina: Edufpi, 2019.

SOIHET, Rachel. Mulheres pobres e violência no Brasil urbano. In: PRIORE, Mary del (Org.). História das Mulheres no Brasil. São Paulo: Contexto, 2004. p. 304-335. Organização de Textos: Carla Bassanezi.

Sites

http://www.adorocinema.com/series/serie-22943/

Revista Caminhos da Educação: diálogos, culturas e diversidades. CAEDU/UFPI

Teresina, Brasil, v. 1, n. 2, p. 60-86, maio/agosto de 2019.

ISBN: 2675-1496 DOI: https://doi.org/10.26694/caedu.v1i2.9910 


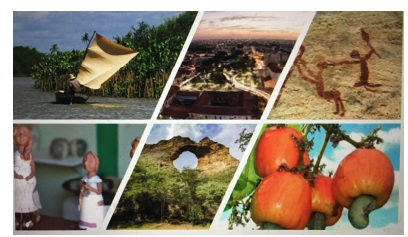

ISBN: 2675-1496 DOI: https://doi.org/10.26694/caedu.v1i2.9910

https://exame.abril.com.br/negocios/estagnacao-base-de-usuarios-da-netflix-no-brasilcresce-cada-vez-menos/

https://olhardigital.com.br/pro/noticia/saiba-como-surgiu-a-ideia-da-netflix/65227

https://www.nolar.com.br/direitos-da-empregada-domestica/

Série

COISA mais Linda. Direção de Caíto Ortiz, Hugo Prata e Julia Rezende. Produção de Beto Gauss e Francesco Civita. Roteiro: Giuliano Cedroni e Heather Roth. Rio de Janeiro: Netflix, 2019. Son., color. Disponível em: <https://www.netflix.com/title/80208298>. Acesso em: 10 ago. 2019.

RECEBIDO: 05/04/2019

APROVADO: $16 / 06 / 2019$ 